\title{
BMJ Open The chronic kidney disease Water Intake Trial (WIT): results from the pilot randomised controlled trial
}

\author{
William F Clark, ${ }^{1}$ Jessica M Sontrop, ${ }^{1,2}$ Shih-Han Huang, ${ }^{1}$ Kerri Gallo, ${ }^{2}$ \\ Louise Moist, ${ }^{1,2}$ Andrew A House, ${ }^{1}$ Matthew A Weir, ${ }^{1}$ Amit X Garg ${ }^{1,2}$
}

To cite: Clark WF,

Sontrop JM, Huang S-H, et al. The chronic kidney disease Water Intake Trial (WIT): results from the pilot randomised controlled trial. BMJ Open 2013;3:e003666. doi:10.1136/bmjopen-2013003666

- Prepublication history for this paper is available online. To view these files please visit the journal online (http://dx.doi.org/10.1136/ bmjopen-2013-003666).

Received 25 July 2013 Revised 31 October 2013 Accepted 20 November 2013

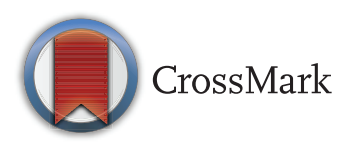

\footnotetext{
${ }^{1}$ Division of Nephrology, Department of Medicine, London Health Sciences Centre, London, Ontario, Canada

${ }^{2}$ Department of Epidemiology \& Biostatistics, Western University, London, Ontario, Canada
}

Correspondence to Dr William F Clark; William.Clark@Ihsc.on.ca

\begin{abstract}
Background and objectives: Increased water intake may benefit kidney function. Prior to initiating a larger randomised controlled trial (RCT), we examined the safety and feasibility of asking adults with chronic kidney disease (CKD) to increase their water intake.
\end{abstract}

Design, setting, participants and measurements: Beginning in October 2012, we randomly assigned 29 adults with stage 3 CKD (estimated glomerular filtration rate (eGFR) $30-60 \mathrm{~mL} / \mathrm{min} / 1.73 \mathrm{~m}^{2}$ and albuminuria) to one of the two groups of water intake: hydration $(n=18)$ or standard $(n=11)$. We asked the hydration group to increase their water intake by 1.0-1.5 L/day (in addition to usual intake, depending on sex and weight) for 6 weeks, while the control group carried on with their usual intake. Participants collected a $24 \mathrm{~h}$ urine sample at baseline and at 2 and 6 weeks after randomisation. Our primary outcome was the between-group difference in change in $24 \mathrm{~h}$ urine volume from baseline to 6 weeks.

Results: (63\%)of participants were men, $81 \%$ were Caucasians and the average age was 61 years (SD 14 years). The average baseline eGFR was $40 \mathrm{~mL} / \mathrm{min} /$ $1.73 \mathrm{~m}^{2}$ (SD $11 \mathrm{~mL} / \mathrm{min} / 1.73 \mathrm{~m}^{2}$ ); the median albumin to creatinine ratio was $19 \mathrm{mg} / \mathrm{mmol}$ (IQR 6-74 mg/ $\mathrm{mmol}$ ). Between baseline and 6-week follow-up, the hydration group's average $24 \mathrm{~h}$ urine volume increased by $0.7 \mathrm{~L} /$ day (from 2.3 to $3.0 \mathrm{~L} /$ day) and the control group's $24 \mathrm{~h}$ urine decreased by $0.3 \mathrm{~L} /$ day (from 2.0 to $1.7 \mathrm{~L} /$ day; between-group difference in change: $0.9 \mathrm{~L} /$ day $(95 \% \mathrm{Cl} 0.4$ to $1.5 ; \mathrm{p}=0.002))$. We found no significant changes in urine, serum osmolality or electrolyte concentrations, or eGFR. No serious adverse events or changes in quality of life were reported.

Conclusions: A pilot RCT indicates adults with stage 3 CKD can successfully and safely increase water intake by up to $0.7 \mathrm{~L} /$ day in addition to usual fluid intake.

Trial registration Registered with Clinical Trialsgovernment identifier: NCT01753466.

\section{BACKGROUND}

Evidence from animal and human studies suggests a specific beneficial effect of water intake on the kidney. ${ }^{1-10}$ Increased water intake suppresses plasma vasopressin, ${ }^{6}{ }^{11}$ which is an

\section{Strengths and limitations of the study}

- The strength of this pilot randomised controlled trial was that it fulfilled the CONSORT document guidelines. It provided a clear signal of safety feasibility and the absence of a negative impact on the quality of life of the hydration intervention relative to the control chronic kidney disease population studied.

- The weaknesses of the study are that it was only of 6 weeks duration and that the separations, although consistent, may not be observed in the 1 year anticipated large randomised controlled trial. Another limitation of this pilot is that there are only 29 participants who were studied and thus the results may not be representative of a much larger population study. These are inevitable weaknesses or limitations of a pilot study, but even with these small numbers, the signal concerning safety and efficacy was clear and significant.

antidiuretic hormone that regulates thirst and water conservation in mammals. While essential for water regulation, vasopressin has vasoconstrictive effects and there is evidence that increased plasma levels can have negative effects on renal haemodynamics, blood pressure and ventricular function. ${ }^{12-18}$ In animal models, an increased water intake has been shown to reduce proteinuria and slow the progression of chronic kidney disease (CKD). ${ }^{6} 8$ In humans, several observational studies report positive associations between greater water intake and kidney function. ${ }^{1-4}{ }^{10}$ In a recently published prospective cohort study of 2000 Canadian adults without kidney disease, higher urine volume at baseline was associated with slower renal decline over follow-up. ${ }^{1}$ Similarly, in two cross-sectional analyses of Australian and American cohorts, higher selfreported water intake was associated with better kidney function. ${ }^{2}{ }^{10}$ Most recently, researchers identified chronic dehydration from heat stress as the most likely causal factor in a perplexing epidemic of CKD in Central America. $^{3} 4$ 
Taken together, these findings support a protective effect of greater water intake on the kidney; however, evidence from a large, well-designed randomised controlled trial is needed to determine if higher water intake can slow the rate of kidney function decline.

We designed a randomised controlled trial to test whether increased water intake can slow renal decline in adults with stage $3 \mathrm{CKD}$. However, due to the expressed concerns by the clinicians about increasing hydration in patients with CKD and the potential for fluid overload and water intoxication, we conducted a 6 -week pilot trial to assess the feasibility, safety and quality of life changes that occur when adults with CKD increase their water intake by $1.0-1.5 \mathrm{~L} /$ day (in addition to usual consumed beverages) for 6 weeks. ${ }^{12}$ This report describes the results of this pilot trial.

\section{METHODS}

\section{Design, setting and participants}

We conducted a parallel-group randomised controlled pilot trial (London, Ontario, Canada 2012-2013). Adult patients (age 30-80 years) attending a CKD Clinic at the London Health Sciences Centre (Victoria Hospital), who met the study's eligibility criteria, were invited to participate. We defined CKD (stage 3) as the presence of reduced kidney function (at least one estimated glomerular filtration rate (eGFR) $30-60 \mathrm{~mL} / \mathrm{min} / 1.73 \mathrm{~m}^{2}$ ) and proteinuria (albumin/creatinine $>2.8 \mathrm{mg} / \mathrm{mmol}$ (if female) or $>2.0 \mathrm{mg} / \mathrm{mmol}$ if male) from a spot urine sample or trace protein (albustix)). We used the CKD Epidemiology Collaboration (CKD-EPI) equation to calculate eGFR $^{19}$ from serum creatinine. We excluded those who met any of the following criteria: required fluid restriction $(<1.5 \mathrm{~L} /$ day $)$ for kidney disease, heart failure or liver disease; lived too far from the clinic to reliably participate in follow-up visits; self-reported fluid intake $\geq 10$ cups/day or $24 \mathrm{~h}$ urine volume $\geq 3 \mathrm{~L}$; enrolled in another trial that could influence the intervention, outcomes or data collection of this trial; received a dialysis treatment in the past month; kidney transplant recipient (or on waiting list); pregnant or breastfeeding; a history of symptomatic kidney stones in the past 5 years; less than 2 years life expectancy; serum sodium $\leq 130 \mathrm{mmol} / \mathrm{L}$; serum calcium $>2.6 \mathrm{mmol} / \mathrm{L}$ and currently taking lithium (affects thirst and urination ${ }^{20}$ ) or high daily doses of the following diuretics: hydrochlorothiazide $>25 \mathrm{mg} /$ day, indapamide $>1.25 \mathrm{mg} /$ day, furosemide $>40 \mathrm{mg}$ /day or metolazone $>2.5 \mathrm{mg} /$ day.

\section{Enrolment}

The patient's nephrologist invited interested patients to speak with a research assistant who explained the study, confirmed eligibility and obtained consent. To confirm that urine volume was less than $3 \mathrm{~L} /$ day at baseline, the participants were asked to provide a $24 \mathrm{~h}$ urine sample within 2 weeks of enrolment. A research assistant arranged to meet the participants the same day the $24 \mathrm{~h}$ collection was completed, and a blood sample for baseline laboratory measures was obtained. Once eligibility was confirmed, the participants were randomised to the hydration group or the control group and those in the hydration group were instructed on the intervention.

\section{Randomisation and intervention}

Participants were randomised in block sizes of three by computer-generated randomisation to the hydration group or the control group (2:1), stratified by gender. An unequal randomisation of $2: 1$ vs $1: 1$ was chosen to provide experience delivering the hydration intervention to more patients. The random allocation was concealed to patients, their healthcare providers and research staff. The hydration group was asked to drink $1-1.5 \mathrm{~L}$ water per day for 6 weeks, in addition to usual consumed beverages, depending on sex, weight and $24 \mathrm{~h}$ urine osmolality (tables 1 and 2). To encourage adherence to the allocated water intake, the participants in both groups were given reusable drinking containers and research personnel maintained regular contact with the participants and enquired about regimen tolerance and adherence. Participants randomised to the control group were advised to continue usual fluid intake or to decrease fluid intake by 1-2 cups/day depending on their baseline $24 \mathrm{~h}$ urine osmolality (table 2). Continued hydration coaching based on $24 \mathrm{~h}$ urine osmolality was conducted after the second $24 \mathrm{~h}$ urine sample (2 weeks after randomisation) was obtained (table 2). ${ }^{21}$

\section{Objectives and outcomes}

The primary aim of this pilot trial was to assess the feasibility and safety of asking adults with stage 3 CKD to follow the above hydration intervention. Our primary assessment of feasibility was to compare the between-group change in

Table 1 Hydration intervention by sex and weight

\begin{tabular}{|c|c|c|c|c|c|}
\hline \multirow[b]{2}{*}{ Sex } & \multirow[b]{2}{*}{ Weight (kg) } & \multicolumn{4}{|c|}{ Recommended increase in water intake } \\
\hline & & Daily total (L/day) & Breakfast & Lunch & Dinner \\
\hline \multirow[t]{2}{*}{ Women } & $<70$ & 1.0 & 250 mL (1 cup) & 500 mL (2 cups) & 250 mL (1 cup) \\
\hline & $\geq 70$ & 1.25 & $250 \mathrm{~mL}$ (1 cup) & 500 mL (2 cups) & $500 \mathrm{~mL}$ (2 cups) \\
\hline \multirow[t]{2}{*}{ Men } & $<70$ & 1.25 & 250 mL (1 cup) & 500 mL (2 cups) & $500 \mathrm{~mL}$ ( 2 cups) \\
\hline & $\geq 70$ & 1.5 & $500 \mathrm{~mL}$ (2 cups) & 500 mL (2 cups) & $500 \mathrm{~mL}$ (2 cups) \\
\hline
\end{tabular}




\begin{tabular}{|c|c|c|}
\hline $\begin{array}{l}\text { Trial } \\
\text { group }\end{array}$ & $\begin{array}{l}\text { Urine osmolality } \\
\text { (mOsm/kg) }\end{array}$ & Hydration coaching \\
\hline \multirow[t]{3}{*}{ Hydration } & $<300$ & $\begin{array}{l}\text { Maintain current water } \\
\text { intake }\end{array}$ \\
\hline & $300-500$ & $\begin{array}{l}\text { Increase water intake by } \\
\text { an additional } 1-2 \text { cups/ } \\
\text { day }\end{array}$ \\
\hline & $>500$ & $\begin{array}{l}\text { Increase water intake by } \\
\text { an additional } 2 \text { cups/day }\end{array}$ \\
\hline \multirow[t]{3}{*}{ Control } & $<300$ & $\begin{array}{l}\text { Reduce water intake by } \\
1-2 \text { cups/day* }\end{array}$ \\
\hline & $300-500$ & $\begin{array}{l}\text { Reduce water intake by } \\
1 \text { cup/day* }\end{array}$ \\
\hline & $>500$ & $\begin{array}{l}\text { Maintain current water } \\
\text { intake }\end{array}$ \\
\hline
\end{tabular}

$24 \mathrm{~h}$ urine volume from baseline to 6-week follow-up. Our primary safety endpoints were the proportion of participants with a serum sodium $<130 \mathrm{mmol} / \mathrm{L}$ at any point during study follow-up and the between-group change in serum sodium values. Finally, we compared between-group changes in kidney function, physical health and health-related quality of life (HRQL).

\section{Data collection and measures}

Baseline data included the most recent list of medications, height, weight and blood pressure. Seated blood pressure was measured with a Welch Allyn Sphygmomanometer using a standardised protocol. Weight was measured at baseline and again at the final follow-up using a gravityweighted scale. At baseline and 6 weeks after randomisation, participants completed a survey on their medical history and answered questions about their HRQL from the Kidney Disease Health Related Quality of Life (KDQOL-SF) questionnaire. ${ }^{22} 23$ Two weeks after randomisation, all participants completed a 3-day diet record and had a 45 min consultation with a renal dietician. Diet records were analysed for daily protein, sodium and fluid intake. Blood samples were obtained at baseline and every 2 weeks after randomisation. The participants collected a $24 \mathrm{~h}$ urine sample at baseline and again between 2 and 6 weeks after randomisation.

\section{Laboratory analysis}

Serum creatinine was measured using the isotope dilution/mass spectroscopy-traceable enzymatic method. Blood sodium concentrations were measured with indirect ion-selective electrodes and urea concentrations were measured with enzymatic photometric methods. Serum osmolality was measured by freezing point depression using an advanced instrument MicroOsmometer. The serum cystatin $\mathrm{C}$ was measured by nephelometry. Twenty-four-hour urine creatinine was measured using enzymatic methods and the $24 \mathrm{~h}$ albumin:creatinine ratio was analysed using an immunoturbimetric assay. Twenty-four-hour urine sodium and potassium were measured with indirect ionselective electrodes. Urine specific gravity was measured using a digital urine-specific gravity PEN Refractometer (PEN-Urine S.G.)

\section{Statistical analysis}

Normally distributed data were summarised using means and SD; non-normally distributed data were summarised using medians and IQR. We followed an intent-to-treat analysis: all randomised participants were included in the analysis and analysed according to group assignment. We compared the between-group change in urine volume, kidney function, electrolytes and other variables using the independent $\mathrm{t}$ test or Mann-Whitney $\mathrm{U}$, as appropriate. Bivariate correlations were estimated using the Pearson product-moment correlation coefficient $(r)$. No subgroup analyses were performed. Data were analysed using IBM SPSS Statistics V.19.

\section{RESULTS}

Enrolment occurred between 16 October 2012 and 29 January 2013. During this time, 74 patients met the initial eligibility criteria and were approached for trial participation. A flow diagram of patient selection and follow-up is presented in figure 1. In total, 29 participants were randomised. One participant withdrew from the study after randomisation due to a flare-up of Crohn's disease.

Sixty-three per cent of the participants were men, $81 \%$ were Caucasian; and the average age was 61 years (SD 14); $54 \%$ of the participants had diabetes and $86 \%$ had hypertension. The average eGFR at baseline was $40 \mathrm{~mL} / \mathrm{min} /$ $1.73 \mathrm{~m}^{2}$ (SD 11). Characteristics of participants randomised to the hydration $(n=18)$ and control groups $(n=11)$ are shown in table 3. Although randomisation protects against baseline differences between the groups, baseline differences may occur in smaller samples such as this. Participants randomised to the control group were older, had more comorbidities and had more diuretic use compared with those in the hydration group.

\section{A $24 \mathrm{~h}$ urine volume}

Change in $24 \mathrm{~h}$ urine volume is shown in figure 2 and table 4 . Between baseline and 6-week follow-up, the hydration group's $24 \mathrm{~h}$ urine volume increased by $0.7 \mathrm{~L} /$ day (from $2.3 \mathrm{~L}$ to $3.0 \mathrm{~L} /$ day) and the control group's $24 \mathrm{~h}$ urine volume decreased by $0.3 \mathrm{~L} /$ day (from $2.0 \mathrm{~L}$ to $1.7 \mathrm{~L} /$ day; between-group difference in change: $0.9 \mathrm{~L} /$ day; $95 \%$ CI 0.4 to $1.5 ; \mathrm{p}=0.002)$. The difference between groups at the last follow-up was $1.3 \mathrm{~L} /$ day $(\mathrm{p}=0.005)$.

\section{Serum sodium}

Serum sodium concentration remained above $130 \mathrm{mmol} / \mathrm{L}$ for all participants at all follow-up points and was similar between the groups at all comparison points (table 4). Change from baseline did not differ 


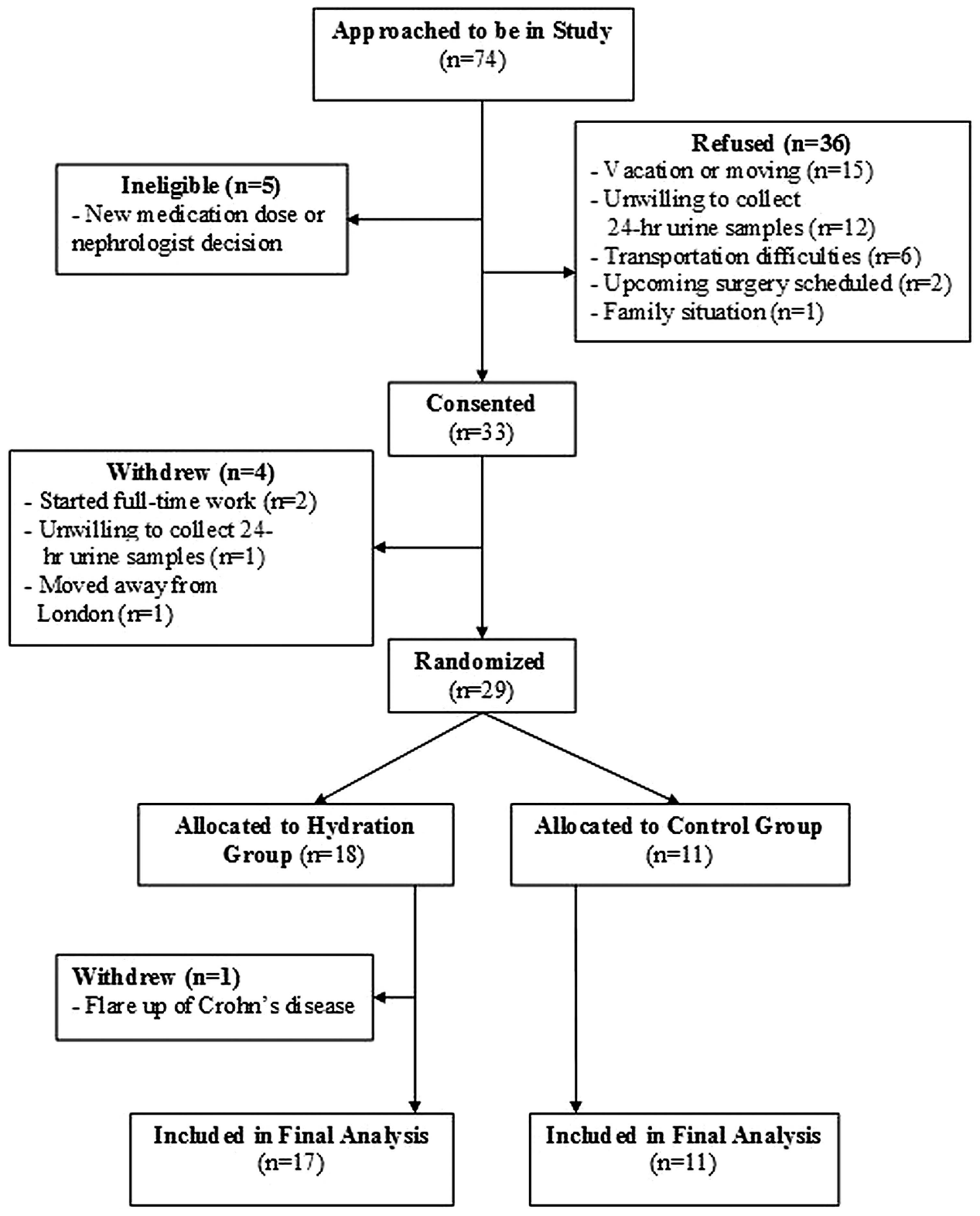

Figure 1 Flow diagram of participant selection and follow-up.

between the groups $(p=0.37)$. At the final follow-up, the average sodium concentration was $138 \mathrm{mmol} / \mathrm{L}$ in both groups.

\section{Kidney function, electrolytes and osmolality}

Measures of kidney function, electrolytes and osmolality remained within expected ranges for patients with CKD (table 4). Urine osmolality decreased by $76 \mathrm{mOsm} / \mathrm{kg}$ in the hydration group and by $19 \mathrm{mOsm} / \mathrm{kg}$ in the control group; $\mathrm{p}=0.27$ for between-group change. The $24 \mathrm{~h}$ urine osmolality did not vary significantly with eGFR at baseline or follow-up. $24 \mathrm{~h}$ urine creatinine remained within $10 \%$ of baseline values.

HRQL and diet

No appreciable differences in HRQL were evident (table 5). Although the hydration group reported a higher frequency of night-time urination at final follow-up (2.6 vs $1.8)$, HRQL sleep scores were similar between the groups at final follow-up ( 82 in both groups; $\mathrm{p}=0.46$ ). Average intakes of sodium and protein (measured from a 3-day diet record 2 weeks after randomisation) were similar between the hydration and control groups (average sodium intake was 259 (SD 275) and $201 \mathrm{mmol} /$ day (SD $161)$, respectively $(\mathrm{p}=0.56)$; average protein intake was 1.1 (SD 0.2) and $1.1 \mathrm{~g} / \mathrm{kg} /$ day (SD 0.3 ), respectively $(p=0.52)$ ). Body mass index was similar between the hydration and control groups at baseline (table 1) and was $30 \mathrm{~kg} / \mathrm{m}^{2}$ in each group at the 6 -week follow-up $(\mathrm{p}=0.28$ for between-group change). As shown in figure 3 , the average self-reported fluid intake (2 weeks after randomisation) was strongly correlated with $24 \mathrm{~h}$ urine volume $(\mathrm{r}=0.84 ; \mathrm{p}<0.001)$. As well, mean fluid intake was significantly higher in the hydration group than in the control 
Table 3 Baseline characteristics by treatment assignment

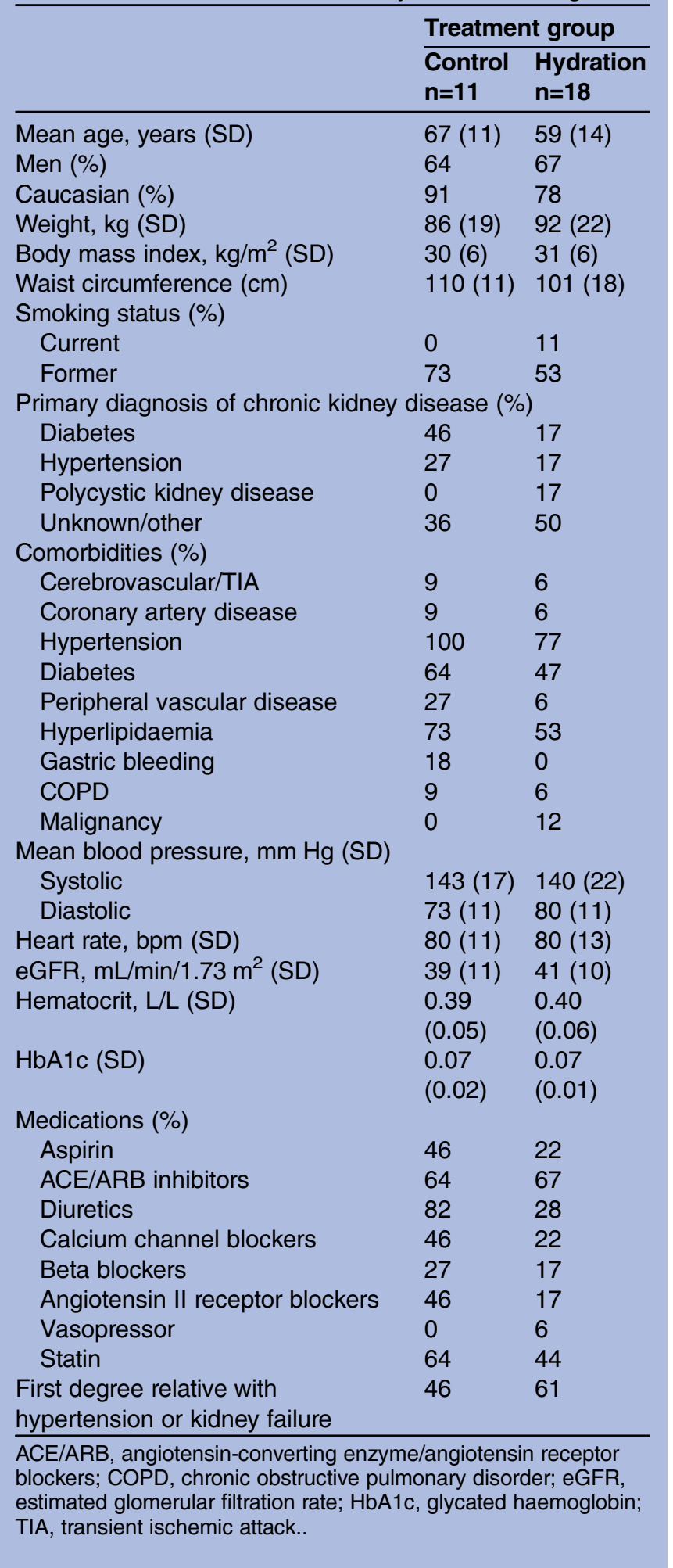

group: $2.8 \mathrm{~L} /$ day (SD 0.8) vs $1.9 \mathrm{~L} /$ day (SD 0.5), respectively; $\mathrm{p}=0.002$.

\section{Adverse events}

No serious adverse events were reported. One patient in the hydration group reported transient nausea; however,

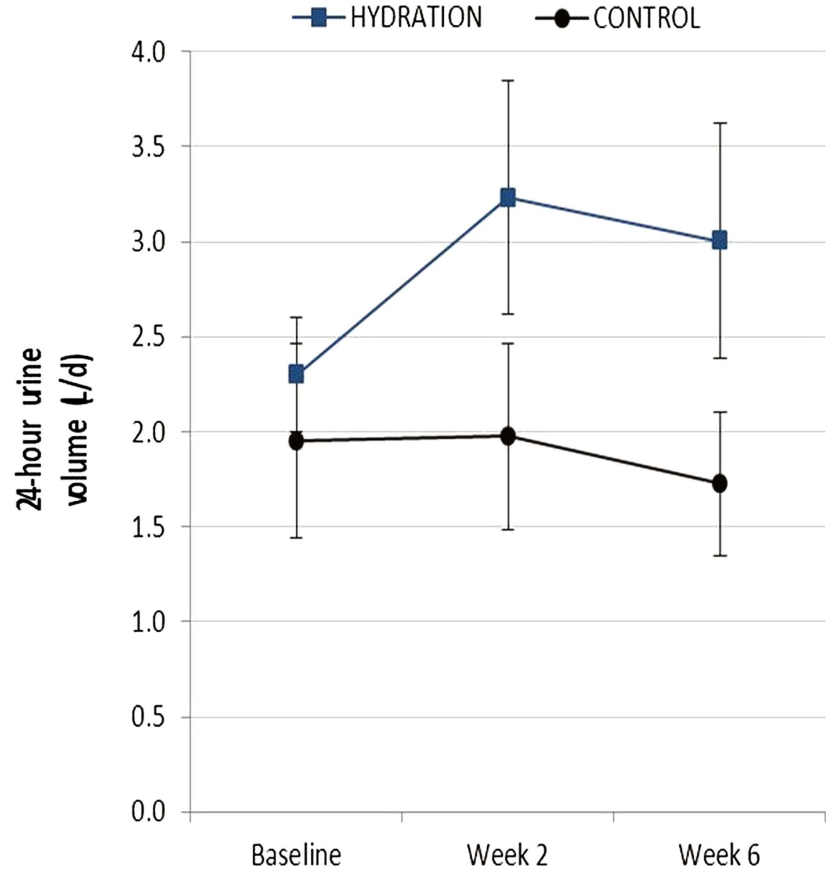

Figure 2 Change in $24 \mathrm{~h}$ urine volume after randomisation to hydration or control intervention.

serum sodium was $140 \mathrm{mmol} / \mathrm{L}$, eGFR was $44 \mathrm{~mL} / \mathrm{min} /$ $1.73 \mathrm{~m}^{2}$ and no other symptoms were noted. One patient in the control group had low urine potassium 2 weeks after randomisation; however, this was due to severe diarrhoea unrelated to study participation. Participants' primary care physicians and treating nephrologists were notified and patients were followed up with no further concerns. No other adverse events were reported.

\section{DISCUSSION}

In this randomised controlled pilot trial, patients with CKD were able to successfully and safely follow being allocated either to a higher or usual oral water intake over a 6-week period. Participants randomised to the hydration group increased their $24 \mathrm{~h}$ urine volumes from $2.3 \mathrm{~L}$ to $3.0 \mathrm{~L} /$ day; in contrast, among controls, $24 \mathrm{~h}$ urine volume decreased by $0.2 \mathrm{~L} /$ day. There was consistent between-group separation of the $24 \mathrm{~h}$ urine volumes in the follow-up. Electrolytes, osmolality and parameters of kidney function remained within the expected ranges for patients with CKD. ${ }^{24}$ Importantly, the serum sodium was similar between the groups at all comparison points and all values remained above $130 \mathrm{mmol} / \mathrm{L}$. As well, HRQL, social functioning, sleep and appetite quality remained similar between groups. No serious adverse events were observed. We are using these pilot data to inform elements of a larger randomised controlled trial to understand the outcomes of an increased water intake in CKD.

While many observational studies suggest a beneficial effect of increased hydration on the kidney, ${ }^{1-4}{ }^{10}$ to our 
Table 4 Change in clinical variables between prerandomisation and 6-week postrandomisation*

\begin{tabular}{|c|c|c|c|c|c|c|c|}
\hline & \multicolumn{2}{|c|}{ Prerandomisation } & \multicolumn{2}{|c|}{ Postrandomisation } & \multicolumn{2}{|c|}{ Change from baseline† } & \multirow{2}{*}{$\begin{array}{l}\text { p } \\
\text { Value }\end{array}$} \\
\hline & Control & Hydration & Control & Hydration & Control & Hydration & \\
\hline $24 \mathrm{~h}$ urine volume, $\mathrm{L}$ & $2.0(0.7)$ & $2.3(0.6)$ & $1.7(0.6)$ & $3.0(1.2)$ & $-0.2(0.4)$ & $0.7(1.0)$ & 0.002 \\
\hline $24 \mathrm{~h}$ urine creatinine, $\mathrm{mmol} / \mathrm{day}$ & $10.9(4.3)$ & $13.0(4.0)$ & $10.2(3.6)$ & $13.5(4.7)$ & $-0.8(1.7)$ & $0.7(2.3)$ & 0.08 \\
\hline $24 \mathrm{~h}$ urine sodium, $\mathrm{mmol} / \mathrm{day}$ & $155(68)$ & $163(68)$ & $114(66)$ & $148(55)$ & $-41(29)$ & $-15(41)$ & 0.10 \\
\hline $24 \mathrm{~h}$ urine potassium, $\mathrm{mmol} / \mathrm{day}$ & $58(30)$ & 69 (32) & $56(25)$ & $71(34)$ & $-2.0(19)$ & $2.3(15)$ & 0.53 \\
\hline $24 \mathrm{~h}$ urine urea, $\mathrm{mmol} / \mathrm{day}$ & $344(136)$ & $388(136)$ & $304(116)$ & $407(116)$ & $-40(66)$ & 19 (82) & 0.07 \\
\hline $24 \mathrm{~h}$ urine osmolality, $\mathrm{mOsm} / \mathrm{kg}$ & 430 (123) & $393(161)$ & $410(75)$ & 317 (110) & $-19(97)$ & $-76(149)$ & 0.27 \\
\hline $\begin{array}{l}24 \mathrm{~h} \text { urine } \mathrm{ACR}, \mathrm{mg} / \mathrm{mmol} \text {, } \\
\text { median (IQR) }\end{array}$ & $20(7,77)$ & $16(6,60)$ & $17(6,86)$ & $16(5,78)$ & $-0.6(-8,9.2)$ & $0.9(-2.7,21.5)$ & 0.69 \\
\hline Serum sodium, $\mathrm{mmol} / \mathrm{L}$ & $139(2.7)$ & $138(2.2)$ & $138(3.4)$ & $138(1.8)$ & $-1.5(2.9)$ & $-0.5(2.7)$ & 0.37 \\
\hline Serum urea, $\mathrm{mmol} / \mathrm{L}$ & $12(3)$ & $12(3)$ & $13(3)$ & $12(4)$ & $1.0(2.6)$ & $0.6(2.6)$ & 0.69 \\
\hline Serum osmolality, mOsm/kg & $305(10)$ & $302(6)$ & $305(10)$ & $302(7.3)$ & $0.0(3.7)$ & $0.06(5.7)$ & 0.98 \\
\hline eGFR, $\mathrm{mL} / \mathrm{min} / 1.73 \mathrm{~m}^{2}$ & $39(11)$ & $42(10)$ & $38(12)$ & $41(10)$ & $-1.8(5)$ & $-0.8(4.0)$ & 0.61 \\
\hline Cystatin C, mg/L & $1.6(0.5)$ & $1.6(0.4)$ & $1.6(0.5)$ & $1.6(0.5)$ & $0.0(0.2)$ & $0.0(0.2)$ & 0.90 \\
\hline Specific gravity (g) & $1.01(0.01)$ & $1.01(0.01)$ & $1.01(0.01)$ & $1.01(0.01)$ & $-0.01(0.01)$ & $-0.01(0.01)$ & 0.89 \\
\hline
\end{tabular}

knowledge, there are no previous clinical trials of increased water intake in adults with CKD. The clinical trials of increased fluid intake in other patient groups (eg, overweight adults, elderly men and patients with polycystic kidney disease or kidney stones) demonstrate no adverse effects. These studies instructed participants to increase water intake by $1-3 \mathrm{~L} /$ day. In particular, Spigt $e t a l^{25-27}$ conducted several studies of healthy elderly men, and showed that an increased fluid intake of $1 \mathrm{~L} /$ day, on an average, was safe in terms of serum sodium, eGFR and quality of life $(n=142)$, and can be sustained over a 6-month period. Furthermore, in a subset of 44 elderly men, a $2 \mathrm{~L}$ increase in fluid intake for up to 2 months was associated with improvement in lower bladder function. ${ }^{25-27}$ Similar to the Spigt's study, ${ }^{27}$ the participants in the hydration group experienced a significant increase in nocturia; however, this was not associated with any measurable changes in HRQL. Although increased water intake is known to be the most effective therapeutic measure to prevent kidney stones, surveys of patients with recurrent kidney stones show poor compliance with prescriptions for increased water intake. ${ }^{28}$ Wang et $a l^{21}$ recently reported results of a water prescription study in eight patients with autosomal dominant polycystic kidney disease who were asked to drink $0.4-1.4 \mathrm{~L} /$ day of water for 5 days, in addition to usual fluid intake. Three $24 \mathrm{~h}$ urine samples were collected in the week preceding the intervention and again during the week of the intervention and participants were able to achieve their targets (mean $24 \mathrm{~h}$ urine volume increased by about $0.8 \mathrm{~L} /$ day), albeit for a brief period of study. In contrast, our pilot study of patients with CKD (eGFR $30-60 \mathrm{~mL} / \mathrm{min} / 1.73 \mathrm{~m}^{2}$ ) was 6 weeks in duration. The hydration group increased

Table 5 Change in health-related quality of life between prerandomisation and 6-week postrandomisation*

\begin{tabular}{|c|c|c|c|c|c|c|c|}
\hline & \multicolumn{2}{|c|}{ Prerandomisation } & \multicolumn{2}{|c|}{ Postrandomisation } & \multicolumn{2}{|c|}{$\begin{array}{l}\text { Change from } \\
\text { baselinet }\end{array}$} & \multirow{2}{*}{$\begin{array}{l}\mathbf{p} \\
\text { Valueł }\end{array}$} \\
\hline & Control & Hydration & Control & Hydration & Control & Hydration & \\
\hline Overall health§ & $68(11)$ & $74(18)$ & $74(18)$ & $78(10)$ & $6(18)$ & $4(15)$ & 0.78 \\
\hline $\begin{array}{l}\text { Affect of physical health on social } \\
\text { functioning§ }\end{array}$ & $68(41)$ & 79 (19) & $80(42)$ & $97(12)$ & $13(52)$ & $8(15)$ & 0.83 \\
\hline Sleep quality§ & $75(22)$ & 79 (19) & $82(18)$ & $82(20)$ & $7(18)$ & $2(14)$ & 0.46 \\
\hline Appetite quality§ & $83(15)$ & $82(18)$ & $88(14)$ & $88(14)$ & $5(8)$ & $5(10)$ & 0.94 \\
\hline \multicolumn{8}{|l|}{ Urinary frequency } \\
\hline Daytime (average per day) & $7.8(1.9)$ & $8.4(3.0)$ & $7.2(2.2)$ & $9.4(4.0)$ & $-0.6(2.0)$ & $1.1(3.1)$ & 0.14 \\
\hline Night-time (average per day) & $2.3(1.7)$ & $1.8(0.8)$ & $1.8(0.7)$ & $2.6(1.2)$ & $-0.5(0.5)$ & $0.7(1.2)$ & 0.01 \\
\hline
\end{tabular}




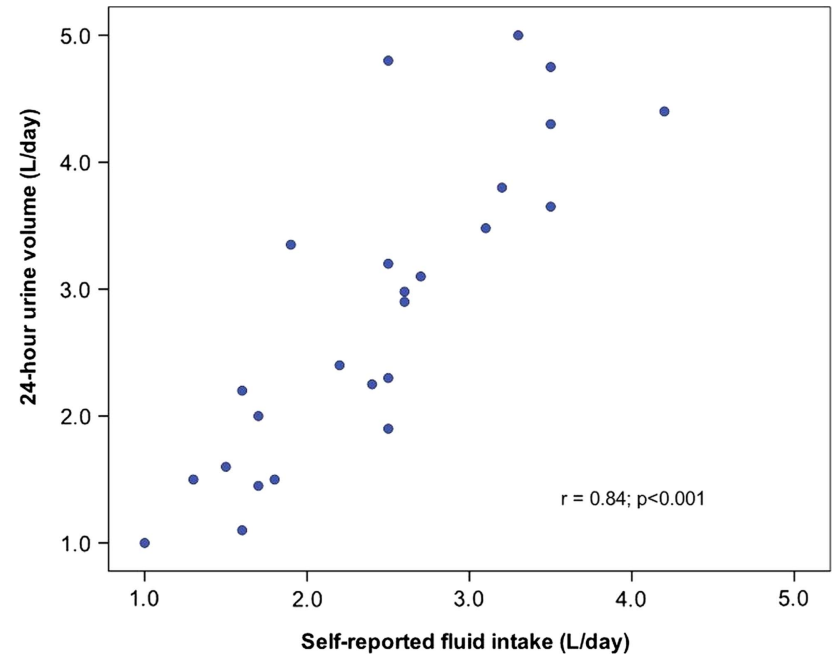

Figure 3 Correlation between $24 \mathrm{~h}$ urine volume and self-reported fluid intake 2 weeks after randomisation ( $r=$ Pearson's correlation coefficient).

their $24 \mathrm{~h}$ urine volume by $0.7 \mathrm{~L} /$ day, and the between-group difference at the final follow-up was $1.3 \mathrm{~L} /$ day, which we attribute to the coaching skills and frequency of telephone follow-up with participants. ${ }^{29-31}$ Urine osmolality decreased to a greater extent in the hydration group compared with the control group (by $19 \%$ vs $5 \%$, respectively); however, this difference was not statistically significant. Although other studies have demonstrated that acute water loading can significantly reduce urine osmolality, ${ }^{11} 32$ these studies evaluated hydration regimens that were much greater (eg, $\geq 3 \mathrm{~L} /$ day compared with 1-1.5 L/day in our study).

Our trial has some limitations that merit discussion. Because it was not possible to blind the participants in this pilot trial (nor in the main trial), both groups were fully informed of the main trial's hypothesis/research question: Does increased hydration reduce progression of CKD? To counteract any potential contamination of our control group being informed about the trial's objectives and potential benefit, we coached controls to not increase their hydration beyond normal intake or thirst. One explanation for the high refusal rate in this pilot phase is that the participants were asked to collect a total of three $24 \mathrm{~h}$ urine samples: one every 2 weeks. However, despite this onerous task, only one patient withdrew from the study after a flare-up of Crohn's disease. Although neither participants nor assessors were blinded, our primary outcome of change in $24 \mathrm{~h}$ urine volume is an objective laboratory measure and therefore less subject to self-report or assessor bias, and $24 \mathrm{~h}$ urine creatinine concentrations remained within $10 \%$ of baseline values for the hydration and control groups. We acknowledge that a $24 \mathrm{~h}$ urine collection may not accurately capture a long-term fluid intake; however, because our primary outcome required participants to collect several $24 \mathrm{~h}$ urine collections in a short period of time, we did not wish to increase respondent burden by requiring a detailed dietary history as well. Nonetheless, we observed a strong $(\mathrm{r}=0.84)$, statistically significant correlation between self-reported fluid intake from a 3-day diet record and $24 \mathrm{~h}$ urine output. As well, despite the small sample size of this pilot trial, the between-group difference in $24 \mathrm{~h}$ urine volumes was statistically significant over follow-up.

Our study demonstrates that increased water intake for 6 weeks in patients with CKD is feasible and safe with no negative impact on quality of life; however, with only 18 patients randomised to the hydration regimen, long-term safety and generalisability are less clear. These are inevitable weaknesses of a pilot study, and we will be monitoring these variables closely in our 12-month randomised controlled trial. We will randomise 700 adults with CKD to the hydration regimen described here, or a control group (1:1). In the main trial, three $24 \mathrm{~h}$ urine collections will be separated over 12 months. We will measure participants' eGFR every 3 months for 12 months, and compare the rate of renal decline between the intervention and control groups. We anticipate that this novel trial will generate important new knowledge about the effect of water intake on kidney function in patients with CKD.

\section{CONCLUSION}

The results of this 6-week pilot study demonstrate that patients with CKD are willing and able to increase water intake by up to $0.7 \mathrm{~L} /$ day (in addition to usual consumed beverages, depending on sex and weight) with no safety concerns.

Funding This study was funded by Danone Research and the Programme of Experimental Medicine, Western University, Canada.

Competing interests WFC received speaking honoraria from and a recently initiated randomised controlled trial funded by Danone Research and the Programme of Experimental Medicine, Western University, Canada.

Ethics approval Ethics approval was obtained from the Western University Research Ethics Board for Health Sciences (Board number is 102787) on 16 August 2012 (registered with the US Department of Health and Human Services IRB 00000940). We experienced administrative difficulties with the ClinicalTrials.gov site, which delayed protocol registration until 9 Nov 2012 (NCT 01753466). Although our first patient was consented on 16 0ct, this patient was not randomised until 26 0ct 2012 (after first $24 \mathrm{~h}$ urine collection was completed).

Provenance and peer review Not commissioned; externally peer reviewed.

Data sharing statement Technical appendix, statistical code and dataset available from the corresponding author at: William.Clark@lhsc.on.ca

Open Access This is an Open Access article distributed in accordance with the Creative Commons Attribution Non Commercial (CC BY-NC 3.0) license, which permits others to distribute, remix, adapt, build upon this work noncommercially, and license their derivative works on different terms, provided the original work is properly cited and the use is non-commercial. See: http:// creativecommons.org/licenses/by-nc/3.0/

\section{REFERENCES}

1. Clark WF, Sontrop JM, Macnab JJ, et al. Urine volume and change in estimated GFR in a community-based cohort study. Clin J Am Soc Nephrol 2011;6:2634-41. 
2. Strippoli GF, Craig JC, Rochtchina E, et al. Fluid and nutrient intake and risk of chronic kidney disease. Nephrology (Carlton) 2011;16:326-34.

3. Brooks DR, Ramirez-Rubio O, Amador JJ. CKD in Central America: a hot issue. Am J Kidney Dis 2012;59:481-4.

4. Peraza S, Wesseling C, Aragon A, et al. Decreased kidney function among agricultural workers in El salvador. Am J Kidney Dis 2012;59:531-40.

5. Bankir L, Bouby N, Trinh-Trang-Tan MM. Vasopressin-dependent kidney hypertrophy: role of urinary concentration in protein-induced hypertrophy and in the progression of chronic renal failure. $A m \mathrm{~J}$ Kidney Dis 1991;17:661-5.

6. Bouby N, Bachmann S, Bichet D, et al. Effect of water intake on the progression of chronic renal failure in the 5/6 nephrectomized rat. Am J Physiol Renal Physiol 1990;258:F973.

7. Bouby N, Ahloulay M, Nsegbe E, et al. Vasopressin increases glomerular filtration rate in conscious rats through its antidiuretic action. J Am Soc Nephrol 1996;7:842-51.

8. Sugiura T, Yamauchi A, Kitamura $\mathrm{H}$, et al. High water intake ameliorates tubulointerstitial injury in rats with subtotal nephrectomy: possible role of TGF-[bgr]. Kidney Int 1999;55:1800-10.

9. Nagao S, Nishii K, Katsuyama M, et al. Increased water intake decreases progression of polycystic kidney disease in the PCK Rat. J Am Soc Nephrol 2006;17:2220-7.

10. Sontrop JM, Dixon SN, Garg AX, et al. Association between water intake, chronic kidney disease and cardiovascular disease: as cross-sectional analysis of NHANES data. Am J Nephrol 2013;37:434-42.

11. Shore AC, Markandu ND, Sagnella GA, et al. Endocrine and renal response to water loading and water restriction in normal man. Clin Sci (Lond) 1988;75:171-7.

12. Torres VE. Vasopressin in chronic kidney disease: an elephant in the room? Kidney Int 2009;76:925-8.

13. Edwards RM, Trizna W, Kinter LB. Renal microvascular effects of vasopressin and vasopressin antagonists. Am J Physiol 1989;256: F274-8.

14. Perico N, Zoja C, Corna D, et al. V1/V2 vasopressin receptor antagonism potentiates the renoprotection of renin-angiotensin system inhibition in rats with renal mass reduction. Kidney Int 2009;76:960-7.

15. Luft FC. Vasopressin, urine concentration and hypertension: a new perspective on an old story. Clin J Am Soc Nephrol 2007;2:196-7.

16. Cirillo M. Determinants of kidney dysfunction: is vasopressin a new player in the arena? Kidney Int 2010;77:5-6.

17. Khan SQ, Dhillon OS, O'Brien RJ, et al. C-Terminal provasopressin (copeptin) as a novel and prognostic marker in acute myocardial infarction. Circulation 2007;115:2103-10.
18. Goldsmith SR. Is there a cardiovascular rationale for the use of combined vasopressin V1a/V2 receptor antagonists? Am J Med 2006;119:S93-6.

19. Levey AS, Stevens LA, Schmid $\mathrm{CH}$, et al. A new equation to estimate glomerular filtration rate. Ann Intern Med 2009;150:604-12.

20. Baylis $\mathrm{PH}$, Heath DA. Water disturbances in patients treated with oral lithium carbonate. Ann Intern Med 1978;88:607-9.

21. Wang CJ, Creed C, Winklhofer FT, et al. Water prescription in autosomal dominant polycystic kidney disease: a pilot study. Clin $\mathrm{J}$ Am Soc Nephrol 2011;6:192-7.

22. Hays RD, Kallich JD, Mapes DL, et al. Development of the kidney disease quality of life (KDQOL TM) instrument. Qual Life Res 1994;3:329-38.

23. Hays RD. Rand Corporation. Kidney Disease Quality of Life Short Form (KDQOL-SF Tm), Version 1.3: a manual for use and scoring. 1997. Rand.

24. Diem K, Lentner C, eds. Documenta Geigy Scientific Tables. 7th edn. Basle, Switzerland: CIBA-GEIGY Ltd, 1973:523, 531-536, 557.

25. Spigt MG, Knottnerus JA, Westerterp KR, et al. The effects of 6 months of increased water intake on blood sodium, glomerular filtration rate, blood pressure, and quality of life in elderly (aged 55-75) men. J Am Geriatr Soc 2006;54:438-43.

26. Spigt $M$, van Schayck $O$, Knipschild $P$, et al. Is it possible to improve elderly male bladder function by having them drink more water? A randomized trial of effects of increased fluid intake/urine output on male lower urinary tract function. Urology 2006;68:1031-6.

27. Spigt MG, Knottnerus JA, van de Beek C, et al. Short-term effects of increased urine output on male bladder function and lower urinary tract symptoms. Urology 2004;64:499-503.

28. Bankir L, Daudon M. Recurrent (as opposed to non-recurrent) stone formers failed to increase urine volume significantly over a 3-y period in spite of recommendations to drink more, and still showed a higher Tiselius index in morning urine. J Am Soc Nephrol 2008;19:294A.

29. Eakin E, Reeves M, Lawler S, et al. Telephone counseling for physical activity and diet in primary care patients. Am J Prev Med 2009;36:142-9.

30. Eakin EG, Lawler SP, Vandelanotte C, et al. Telephone interventions for physical activity and dietary behavior change: a systematic review. Am J Prev Med 2007;32:419-34.

31. McCauley LR, Dyer AJ, Stern K, et al. Factors influencing fluid intake behavior among kidney stone formers. J Urol 2012;187:1282-6

32. Barash I, Ponda MP, Goldfarb DS, et al. A pilot clinical study to evaluate changes in urine osmolality and urine cAMP in response to acute and chronic water loading in autosomal dominant polycystic kidney disease. Clin J Am Soc Nephrol 2010;5:693-7. 